\title{
The translation of Sichuan Opera'S Titles from Chinese Culture Communication Perspective-C-Taking Chinese Names and Culture-Loaded Words as Examples
}

\section{Zhemin Chen}

The Engineering and Technical College of Chengdu University of Technology, Leshan,

Sichuan, China

tinaswansea@163.com

Keywords: Translation of Sichuan opera; Titles of Sichuan opera; Culture communication.

Abstract. Sichuan opera, regarded as the gem of Chinese culture, has an important significance to enhance China's cultural influence and construct the national culture identity. Titles of Sichuan opera play a very important role in Sichuan opera's out going and also condense Chinese culture. However, the huge culture gap between Chinese and western can form the cross-cultural communication barriers. Therefore, this paper, from the Chinese culture communication perspective, will explore suitable translation strategies and principles of Sichuan opera's titles, especially for Chinese names and culture-loaded words, which can efficiently improve cross-culture communication of Sichuan opera along with its protection and inheritance in worldwide.

\section{中国文化传播视角下川剧剧名的翻译 \\ 一以人名和文化词为例 \\ 陈哲敏 \\ 成都理工大学工程技术学院, 乐山, 四川, 中国 \\ tinaswansea@163.com}

关键词：川剧翻译；川剧剧名；文化传播

中文摘要.川剧作为中国民族文化的瑰宝, 对增强中国文化影响力和建构民族文化身份有重 要的意义。川剧剧名是川剧 “走出去” 的一张闪亮名片, 是中国文化的高度浓缩。但由于中 西文化差异较大, 往往会形成跨文化传播隔阂, 因此以传播中华文化为目的, 探寻适合川剧 剧名尤其是文化人名和文化词的翻译策略和翻译原则, 不仅有助于川剧在海外高效地传播, 也有助于川剧在世界范围内的保护与传承。

\section{1. 引言}

在中国戏剧艺术之林中，川剧独树一帜，以其鲜明的民族性、地域性及深厚的文化底蕴 令人惊叹。川剧积淀着中华民族的文化心理、道德观念和审美意识, 是我国灿烂文化的重要 组成部分。将川剧传播至海外会让世界更了解中国, 通过川剧知晓中国悠久的历史、社会伦 理道德和人文价值观。为了使川剧进行有效地对外传播, 川剧的翻译尤其是以川剧为载体的 文化翻译就显得十分重要了。川剧作为非物质文化遗产是一种综合的艺术形式, 川剧翻译也 是一个复杂的体系, 可以从不同角度进行川剧译介研究。本文将从中国文化传播的视角来探 寻川剧剧名中文化人名和文化词的翻译原则和策略。 


\section{2. 川剧剧名的特点}

川剧剧目十分丰富, “《川剧剧目辞典》共收入剧目词条6000余条, 其中有本及存目的 传统剧目4000余个, 新中国建立后改编及创作的剧目2000余个”。（杜建华，王定欧，2008： 103）川剧中有不少剧目源自古老戏曲的经典剧目，还有一些来自于巴蜀文人的改编和原创剧 目, 剧名十分有特色。为了便于观众阅读, 也易于记忆和广泛传播, 川剧剧名简洁凝练, 三 至五个字的剧名最常见。针对不同的剧本，根据川剧剧目的内容，以及预期的受众，川剧剧 名所突出的信息各异，有的意在点明故事的主人翁如《潘金莲》、 《金子》、 《中国公主杜 兰朵》等, 有的突出标识剧目的类型如《白蛇传》、《目连传》、《焚烧记》等, 有的强调 事件发生的地点如《凤仪亭》、《断桥》、《秋江》等, 还有的是概括故事的大致内容如《逼 侄赴科》、《点将责夫》等。川剧剧名是中国文化的浓缩, 这是川剧剧名最主要也是最突出 的特点。无论是沿袭古老的剧目名称, 还是巴蜀文人创新的剧目名称, 在川剧简短的三五个 字的剧名中都映射着中华民族的历史文化、风俗习惯、精神世界和价值观。尤其是川剧剧名 中那些负载文化内涵的人名和文化词，最能体现川剧所承载的地域文化和民族文化。

\section{3. 川剧剧名中人名的翻译}

有一大部分川剧是以附有中华文化内涵的人名为剧名的, 这些剧名人物对中国观众而言 几乎是耳熟能详, 如川剧《许云峰》、《李冰》、《潘金莲》、《杜十娘》等。这些人名在 中国观众心中有着鲜活的形像, 尽管只是一个简单的名字, 由于其负载的中华文化, 在中国 观众的心理上会产生喜怒哀乐等感情上的共鸣。然而对西方受众来说, 这些人名可能比较陌 生, 很难看到或听见人名后立刻达成与中国观众一样的文化共识。正如白靖宇在《文化与翻 译》一书中所述 “翻译作为一种语际间的交际, 不仅是语言转换过程, 也是文化交流的过程, 译者应成为文化的传播者。”（2010：22）

通常在翻译中国人名的时候, 译者倾向于采用音译策略, 通过异化的翻译技巧, 以拼音 的方式呈现中国人名, 使译入语的读者体验异国情调。但是川剧剧名中这些有着文化内涵的 人名, 若用音译的方式进行译介, 从文化传播的角度来看却不太适合。如川剧剧名《许云峰》, 若直接将剧名音译为 “Xu Yunfeng” , 虽然拼音能体现汉语人名的发音, 但这一翻译却忽略 了更多关于 “许云峰” 的深层中华文化信息。对中国战争史和革命史知之甚少的外国观众而 言, 看到这一音译剧名时脑海中不会有中华革命情感体验。因此, 在翻译川剧剧名中的文化 名人时, 不能只停留在音译的基础上, 可以在人名之前或之后添加相应的文化信息, 以此点 明川剧剧名中文化名人所具有的中华文化特征, 即人名所反映的民族精神和民族核心价值观。 在译名 “Xu Yunfeng” 之前添加 “a revolutionary martyr” , 这样外国观众在看到川剧剧名时, 通过 “Xu Yunfeng” 可以体验到中华异国风味, 又能借助 “a revolutionary martyr” 联想到中 华革命烈士的形象，还能映射出这出川剧的革命历史背景。“信息传播的传授双方要有共同 的意义空间, 对符号意义拥有共同的理解, 否则会传而不通, 或导致误解。” (郭庆光, 2011: 5）译名添加了有关 “许云峰” 革命英雄的信息, 使剧名在对外传播的过程中找到中西文化的 契合点。国外以 “英雄主义” 为主题的电影、电视剧较多, 这样的译文使外国观众对许云峰 的认识会更具体，更容易传播中国的革命精神和革命历史，同时又和西方的 “英雄主义、崇 尚自由”等文化观相融合，使原本陌生的川剧剧名有了亲切感和精神上的共鸣。

再如川剧《李冰》, 在中国李冰治水的故事家喻户晓, 俗话说 “李冰治水, 功在当代, 利在千秋” 。李冰是巴蜀文化名人，成都平原能够如此富饶，被人们称为 “天府” 乐土，从 根本上说, 是李冰创建都江堰的结果。司马迁在《史记 - 河渠书》中记载: “蜀守冰業离碓, 辟沫水之害, 穿二江成都之中。此渠皆可行舟, 有余则用溉浸, 百姓飨其利。” 因此, 在翻 译川剧剧名《李冰》时, 也要着重体现人物承载的文化信息, 人名“李冰”用音译为“Li Bing”, 再添加相关的治水信息 “prevents floods by water control” ，体现李冰运用聪明才智，使水旱 从人，造福百姓的历史文化背景。 
川剧《潘金莲》，这出戏是有鬼才之称的魏明伦在进入现代社会后，创作的一部荒诞剧。 在中国潘金莲可以说是一个无人不晓的文学人物, 在施耐庵的《水汻传》中她是一个风流、 不守妇道的女人, 是造成悲剧的罪鬼祸首, 给世人留下了深刻的印象。川剧《潘金莲》也是 围绕中国观众熟悉的这一女性形象进行改编、延展和叙述的，但剧目内容发生了很大变化。 剧中作者虚构了不同朝代与不同国家的人物，有当代女记者，女皇武则天，作家施耐庵，以 及女性安那・卡列尼娜等，让他们在同一时空，对潘金莲的命运发表评论。剧中一些人物的职 业是现代社会才逐渐出现的如法官、当代女记者, 体现出川剧《潘金莲》是以现代的视角来 关注中国妇女的命运。因此在翻译剧名《潘金莲》时, 一方面要关注改编剧的文化创新之处, 突出潘金莲的女性形象，另一方面由于剧本的内容改动较大，在翻译的时候可以给外国观众 留有一定的想象空间，去揭秘围绕这一中国女性发生了什么样的故事。将川剧剧名《潘金莲》 译为 “the woman pan jinlian” ，不仅保留了 “潘金莲” 这一角色所突出的传统与现代中国妇 女命运的文化定位, 同时也能对票房做贡献, 抛出悬念, 引起观众的兴趣, 积极购票入场看 川剧。类似的川剧剧名还有很多如《杜十娘》、《谭记儿》等, 均可采用相似的翻译策略, 分别译为 “Du Shi niang sank angrily her jewel case into a river” 和 “intelligent lady Tan Ji'er”。 这样不仅不会损失剧名的中国风味，还能对其相关的文化信息有所补充，将川剧中的文化符 号一一破解，使外国观众走进川剧、体验中国文化、理解和认同中国文化。

\section{4. 川剧剧名中特色文化词的翻译}

川剧剧名中还包含许多中华文化专有的文化词，它们有着浓厚的中华文化印迹，如川剧 《柴市节》、《乔太守乱点驾春谱》、《拉郎配》、《漂母饭信》、《逼侄赴科》、《踏纱 帽》等剧名中都有中华民族特有的文化符号。但由于这些文化词含义的独特性和文化的不可 复制性，在对其进行译介时必然会出现因文化缺位而导致语言缺位的现象。“文化缺位是指 在不同民族间所存在的事物或观念的或缺现象。语言作为文化的载体，文化的缺位必然导致 语言表层的缺位。”（李建军, 2009:56）在对这些文化词进行翻译时, 译者要深入体会其内 在的文化含义, 不能过度强调译名的异国情调, 用创造新词的方式来指称这些文化词, 而应 尽量将剧名表层的文字信息与其潜在的文化信息相结合，进行文化解读式的翻译，这样才不 会造成译入语读者理解困难，同时也能有效传递原川剧剧名中的中华文化。

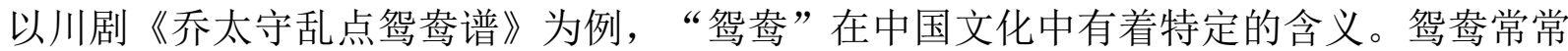
成双入对, 在水面上相亲相爱, 悠闲自得, 因此在中国老百姓的心目中象征着永恒的爱情, 也是终生不渝、一夫一妻的表率。历年来都有文人墨客将 “鹗莺” 比作夫妻来诉说美好的婚 姻爱情，如唐代诗人卢照邻 《长安古意》中就有 “得成比目何辞死，愿作鹗尞不羡仙”，杜 甫《佳人》中有 “合昏尚知时，䀀蓦不独宿” 等有关駕春的名句，显示了中国老百姓通过联

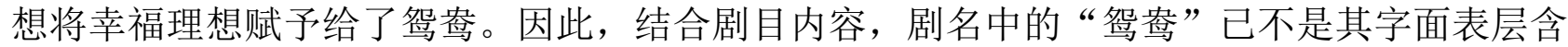
义, 而借用的是 “駕尞” 在中国文化中的引申义, 即婚姻和爱情。《乔太守乱点品尞谱》译 为 “the prefect qiao misjudged cases of marriage”，恰好还原了剧目的核心内容，传递了 “驾 春”的文化象征意义。

再如川剧《柴市节》，在中国柴市是古代常见的木柴交易场所。另外，南宋民族英雄文 天祥就义于柴市, 由此柴市节常引申为民族英雄气节。陈毅在《纪念李大钊同志殉难三十周 年》中有：“人民柴市节，浩气贯长虹。” 就用的是 “柴市节” 来表明李大钊的民族英雄气 节。川剧《柴市节》讲述的正是文天祥英勇就义的故事, 因此将川剧剧名《柴市节》译为 “the martyrdom in the firewood market”，不仅考虑了其本意，更兼顾了文化内涵的引申义。又如 川剧《漂母饭信》中 “信” 指的是楚王 “韩信” ，戏中的 “漂母” 并不是指漂洗丝絮的母亲， 而是指一位漂洗丝絮的老大娘。在翻译剧名 “漂母” 的时候不能望文生义，应将 “漂母” 译 为 “a washerwoman”，完整的剧名为 “A washerwoman aided Han Xin with food” ，一方面显 示了 “漂母” 的身份, 另一方面也显示出 “漂母” 和剧中的另一主角韩信没有亲友关系, 更 能体现出剧目所弘扬的施恩不图报和知感恩的中华民族美德。 
“语言作为中国文化对外传播的基本符号，语言的差异绝不仅仅是表意工具的差异，而 是在其背后往往折射出整个民族生存方式、思维习惯和审美经验的差别”。（隆志秀, 2014: 17) 在译介川剧剧名的专有文化词时, 译者不仅要理解其字面表层含义, 还要深刻体验剧中 深层的中国文化, 这样才能生动、形象、准确地传递川剧剧名中的中华文化内涵, 尽量避免 由于翻译错误使外国观众产生文化信息误读的现象，积极以川剧为桥梁让更多的外国友人走 进中国文化的殿堂, 品味中国文化。

\section{5. 结束语}

川剧剧名中的文化人名对中国观众来说十分熟悉, 看见或听见他们的人名, 就能将其故 事娓娓道来, 他们的音容相貌也能立刻浮现在眼前。因此尽管中文川剧剧名只是简短的人名, 但也能迅速在中国观众和读者心中产生强烈的文化呼应，观赏川剧时脑海中已有的信息被激 活, 很快就能融入到剧目的剧情中。但大部分外国观众在面对这些中华文化人名时, 很难有 与中国观众一样的文化记忆。因此以文化人名命名的川剧在外译时, 要充分考虑剧名中包含 的文化信息，通过翻译使外国观众建立与中国人名相联系的文化符号，即在音译人名的基础 上，添加与人物相关的文化信息，以此提高外国观众对中华文化名人的认知度。川剧人名和 文化词的翻译原则应该是一致的, 译员在翻译时要充分考虑译语读者的文化理解能力和接受 程度。深入理解川剧剧名表层含义之下的引申意义, 力求准确、充分地传递出川剧剧名所负 载的丰富的中华文化信息。通过川剧译名提供的文化信息, 外国观众在看全剧时能仔细品味 剧中人物的特色，尤其是人物及与之联系的剧情所反映的中国历史、文化和核心价值观。

\section{致谢}

本文为四川省教育厅科研项目《四川特色文化对外宣传翻译策略研究》(15SB0266)的阶 段性成果之一。

\section{References}

[1] D. Jianhua, W. Dingou, Sichuan opera, Zhejiang People's Publishing House ,2008.

[2] B. Jinyu, Culture and translation, Beijing China Social Sciences Press,2010.

[3] G. Qingguang, Journalism and communication, Beijing China Renmin University Press , 2011.

[4] L. Jianjun. A study of culture translation, Fudan University Press, 2009.

[5] L. Zhixiu, Cultural misreading: a great challenge of spreading Chinese culture, News Research,vol.6, pp. 17-18, 2014. 